London

Cite this as: $B M J 2020 ; 370: \mathrm{m} 3548$ http://dx.doi.org/10.1136/bmj.m3548 Published: 11 September 2020

\section{Covid-19: Food and drink companies are exploiting pandemic to further their brands, analysis finds}

\section{Matthew Limb}

"Unhealthy" commodity companies around the world are using the covid-19 pandemic for commercial gain in ways that could fuel future disease epidemics, a report has concluded. ${ }^{1}$

Firms trading in alcohol, tobacco, junk foods, gambling, infant milk formula, and fossil fuels are "leveraging" the coronavirus crisis to burnish their brands, build influence, and advance their strategic interests, often to the detriment of wider public health and sustainability goals, shows the research from the NCD Alliance and a multi-university and multi-agency consortium of researchers known as SPECTRUM, based at Edinburgh University, that focuses on the commercial determinants of health and health inequalities.

The authors have called for a tough response from governments and regulators and warned of a "corporate capture of covid 19" with firms using public awareness and fears concerning the pandemic to ward off or weaken regulation and shape tax policies to their advantage.

Lucy Westerman, the NCD Alliance's policy and campaigns manager, said, "There is an irony that companies whose products increase the risk of non-communicable diseases, putting people at higher risk of suffering through the pandemic, have positioned themselves as heroes and partners in the response but have interfered in public policies that seek to protect population health."

Linda Bauld, a professor of public health at Edinburgh University and head of SPECTRUM, said that companies were constantly adapting their engagement with covid-19 and that the findings should be seen as the "tip of the iceberg."

Jeff Collin, co-investigator and professor of global health policy at Edinburgh University, said, "Alcohol and ultraprocessed food companies in particular are desperate to present themselves as partners in global health and development rather than as key drivers of NCD [non-communicable disease] epidemics. And they're extensively working to exploit opportunities arising from the pandemic to promote that framing-one that has worrying potential to shape policy agendas across national and international levels."

In the crowdsourced project the researchers analysed companies' activity over 10 weeks, from early May to mid-July this year, in 94 countries. They amassed 786 submissions, in which the most frequently cited countries were the UK and the US (119 submissions each), followed by Australia, India, Mexico, Brazil, and Jamaica (box 1).

\section{Box 1: Examples of reported activities}

- In Brazil the brewer Karsten adapted its logo to resemble a pair of lungs and attached the slogan "Good beer is like air: you can't live without it," while encouraging consumers to follow three steps to survive with Karsten: "Isolate, use sanitiser, and drink beer for fun."

- Burger King pivoted its marketing in many countries, in enhanced home delivery options with gamification and geolocation apps, encouraging people to stay home to be rewarded with a burger. Westerman said, "They noted, like other brands that wanted to stay connected with consumers, that they wanted to be present in the daily lives of people."

- In the US MCDonalds asked first responders to help the chain to assist them, by offering a free "thank you" meal to healthcare workers who, if they shared a selfie with the franchise, would help it to support the local food bank.

The preliminary analysis examined 100 examples of activities by companies such as Coca-Cola, Pepsico, Nestlé, McDonalds, McCain, Burger King, KFC, Heineken, Kingfisher, and Diageo, though the academics said that many smaller, less well known companies were acting similarly.

The analysis found that companies have adopted four broad approaches: tailored marketing campaigns and stunts tailored to the pandemic; corporate social responsibility and philanthropy programmes; pursuit of partnerships and collaborations, such as with governments, international agencies, and non-governmental organisations; and attempts to shape favourable policy environments.

Westerman said, "Companies rapidly adapted their marketing efforts to reference the health and social concerns associated with the pandemic. A common tactic we found was also to link products with the efforts of health professionals, health emergency services, and other frontline workers."

For example, food and alcohol brands changed their labels to say "thank you to health heroes." Many companies also sought to present themselves and their employees as heroes in the context of the pandemic and in resource-poor countries portrayed themselves as providing essential support to underfunded public services. 
Many breweries and distilleries shifted production to hand gels and sanitisers early in the pandemic. In some cases these were branded, labelled, and packaged and "infused with signature botanicals" to resemble spirits brands.

As governments implemented lockdown restrictions, producers of alcohol and ultraprocessed foods and drinks campaigned to have their products categorised as part of the essential supply chain. Beer producers across Europe called for reductions to sales taxes to support the industry post-covid.

Companies also developed product promotions that exploited the focus on social distancing, utilising face masks as advertising space, and inserting brand images into online video communication platforms.

"The alcohol and gambling sectors have pushed for rapid reopening while introducing measures to reassure they're part of the solution despite being linked to incidents of [covid-19] outbreaks," Westerman said.

Collin said that companies sought to strengthen partnerships and collaborations with governments, United Nations programmes and civil aid agencies such as the Red Cross in order to boost their reputations and "enhance legitimacy." Such access to political elites could ultimately "promote ineffective policies that don't challenge these industries' commercial interests," he said.

The report said that there was a clear need to develop mechanisms to support civil society organisations in managing their interactions with commercial sector actors.

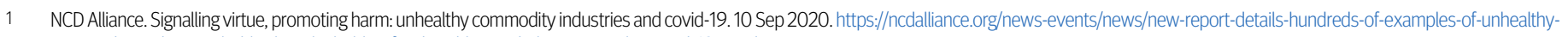
commodity-industries-led-by-big-alcohol-big-food-and-big-soda-leveraging-the-covid-19-pandemic. 